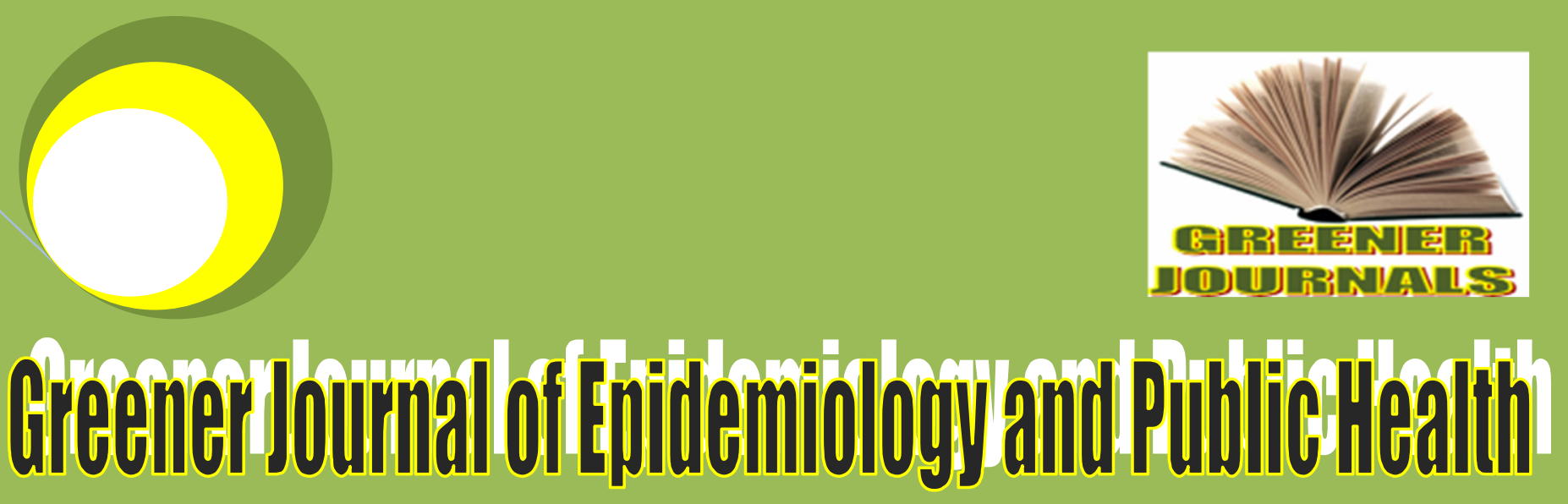

ISSN: 2354-2381

Submitted: $21 / 10 / 2016$

Accepted: 31/10/2016

Published: 29/11/2015

DOI: http://doi.org/10.15580/GJEPH.2016.3.102116188

\title{
Toxicity and Safety of Khat (Catha edulis) Consumption during Pregnancy using Olive Baboons (Papio anubis) as Experimental Models: A
} Prospective Randomised Study

By

Emily Muema

Peter Kinyanjui

James Mbaria

Joseph Nguta

Sharon Chepkwony

Joseph Kamau

Nyamongo Onkoba

Atunga Nyachieo

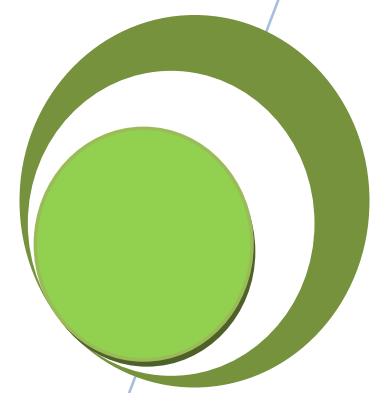




\title{
Toxicity and Safety of Khat (Catha edulis) Consumption during Pregnancy using Olive Baboons (Papio anubis) as Experimental Models: A Prospective Randomised Study
}

\section{Emily Muema ${ }^{1 *}$, Peter Kinyanjui ${ }^{2}$, James Mbaria ${ }^{3}$, Joseph Nguta ${ }^{4}$, Sharon Chepkwony ${ }^{5}$, Joseph Kamau ${ }^{6}$, Nyamongo Onkoba ${ }^{7}$ and Atunga Nyachieo ${ }^{8}$}

\author{
1,3,4 Department of Public Health, Pharmacology and Toxicology, University of Nairobi, P.O. Box 19676-00202 KNH, \\ Nairobi Kenya. \\ 2,6,8 Department of Biochemistry, School of Medicine, University of Nairobi, P.O Box 30197-00100 Nairobi-Kenya. \\ $5,6,7,8$ Institute of Primate Research, P.O. Box 24481-00502 Karen, Nairobi-Kenya.
}

Emails: ${ }^{2}$ pkinyash@yahoo.com, ${ }^{3} \mathrm{mbaria.m@} \mathrm{gmail.com,}{ }^{4}$ jmngut@gmail .com, ${ }^{5}$ shaero09@ yahoo.com, 6kamauvet@yahoo .com, 7bonkoba @gmail.com, ${ }^{8}$ anyachio@yahoo.com

*Corresponding Author's Email: emuema2003 @yahoo .com

\begin{abstract}
Background: The chewing of khat leaves (Catha edulis Forsk) is widely practiced in East Africa and parts of the Middle East, where it forms a deep-rooted social and cultural function. Consumption of Khat is common among men but recently it has extended to women. Biochemical and toxicological effects of Khat on pregnancy and fetal development in lower animals has been noted. Studies on the effect of khat consumption has focused on men thus no data is available on women and especially during pregnancy. This study was conducted to evaluate the effects of khat on liver and kidney functions during pregnancy using olive baboons as experimental models.
\end{abstract}

Methods: Six pregnant olive baboons were randomly assigned into khat treatment group $(n=3)$ that received $100 \mathrm{~m} / \mathrm{s}$ of crude khat at a dose of $5 \mathrm{~g} / \mathrm{kg}$ body weight/week for 8 weeks and the control group $(n=3)$ received normal saline during the second trimester. Blood pressure, temperature and weight changes were measured weekly. Blood was collected to assay for liver and kidney function tests and liver and kidney tissues collected during necropsy for histopathological examinations.

Results: The levels of aminotransferases, urea and creatinine in the khat treated group were significantly elevated compared to those in the control group. There was a decrease of body weight in the dams, fetal birth weight and levels of albumin and sodium in treatment group compared to those in the control group. Kidney and liver tissues of the baboons and their fetuses treated with khat showed necrosis, periportal fibrosis with focal degenerative changes, glomerular degeneration and infiltration with lymphocytes. Blood pressure was not significantly different between the two groups.

Conclusion: The findings show that crude khat may damage the liver and kidneys and modulate the levels of liver enzymes, urea, creatinine and electrolytes essential for liver and kidney functions. Khat is not safe and its use during pregnancy should be discouraged.

Key words: Khat; olive baboons; toxicity; pregnancy; liver and kidney function; safety.

\section{INTRODUCTION}

Improvement in modes of transport in Africa and Arabian Peninsula have allowed for a wide distribution of khat (Catha edulis) into Europe, America and Asia leading to increased consumption (Pennings et al., 2008; Ageely, 2009; Kassim and Croucher 2009). The increase in consumption of khat is due to the euphoric effect of cathinone which also stimulates the central nervous system thereby increasing energy, improving concentration and motivation hence improving work capacity and counteracting fatigue (Nencini and Ahmed, 1989). Khat chewing is addictive and has negative physical, economic and social connotations (Ageely, 2009). 
A study in rats found out that Khat reduced the food consumption, maternal weight gain, in addition to significant increase in resorptions and fetal wastage. Khat administration in utero also reduced the litter size and caused intrauterine growth retardation (Al-Mamary et al., 2002). Examination of tissue sections of the liver from rabbits treated with khat displayed evidence of congestion of the central liver veins as well as acute hepatocellular degenerative and regenerative activities. Also tissue sections of the kidneys showed some lesions, and the degree of the lesion increased as the dose of khat increased (Islam et al., 1994).

It is important to note that while the investigations in humans have provided crucial information into the effects of khat, they mostly have a retrospective background and as such they have several limitations such as the inability of retrospective analysis to permit sample collection and allow controlled parameters such as dosage as would be in a randomized controlled study. Animal models are therefore required to address this issue. Whereas studies in lower animals indicate that khat may have negative effects on body physiology, they do form a good basis of what is expected in higher animals. Extrapolation of these results to humans is limited because of wide phylogenetic gap between humans and lower animals.

Various studies available, in human, on khat chewing/usage and its associated effects mainly on males (Islam et al., 1994; Al-Habori et al., 2002). There is a paucity of information on the effects of khat in females who engage in khat chewing. The available literature is mainly on social-economic effects and based on retrospective study designs with no controlled dosage administration. This studies have not been able to generate data on histopathology of organ tissues such as liver and kidney because it is ethically impossible. Animal models can allow for randomization and controlled dosage administration as well as harvesting of organs for histopathological examination.

To overcome the limitations, olive baboon are ideal models of providing insight into the effects of khat usage during pregnancy. This is because olive baboons are similar to humans in phylogenetics, physiology and reproductive biology (Nyachieo et al., 2013; D'Hooghe et al., 2009) and the results can easily be extrapolated and applied in humans. Indeed, the olive baboon reproductive endocrinology reveal similar hormonal profiles as observed in humans with the peak estrogen serum level at the time of ovulation followed by progesterone secretion increase after the onset of LH surge (Steven, 1997). In addition, since baboons' exhibit perineal sex skin inflation and deflation in response to the levels of estrogen, it is easy to follow the menstrual cycle by daily inspection and recording of perineal sex skin inflation and deflation which correspond with relative precision, to the follicular and luteal phase's respectively (Steven, 1997). Additionally, studies using baboons offer a number of advantages such as possibility to evaluate in a dose controlled study the effects of khat on pregnancy and fetal growth and development with limited ethical restrictions, studies not possible in humans because of the generation time and examination of features not possible without fatalities.

Thus, the study used pregnant olive baboon (Papio anubis) as an experimental animal model system to investigate the effects of khat usage during pregnancy.

\section{MATERIALS AND METHODS}

\section{Ethical statement}

All experimental protocols for this study were reviewed and approved by the nationally accredited Institutional Review committee (IRC) of Institute of Primate Research (IPR) (Karen, Kenya) vide protocol number IRC/06/13. The experiments described herein are in accordance with ARRIVE guidelines (KilKenny et al., 2013). Animals were housed and handled according to international guidelines on care and use of laboratory animals for biomedical use.

\section{Study animals}

Six $(n=6)$ adult female olive baboons were sourced from the Institute of Primate Research (IPR) Nairobi, Kenya. Prior to the study, the animals were screened for tuberculosis, haemoprotozoan parasites and helminths in blood and stool. They were housed in social groups at the biocontainment facility at IPR under $12 \mathrm{~h}$ : $12 \mathrm{~h}$ light: dark cycle, average room temperature of $23^{\circ} \mathrm{C}$ and with a $60 \%$ relative humidity. Animals were fed on commercial pellets (Unga Feeds Ltd, Nairobi, Kenya), supplemented with fruits and vegetables and water was provided ad libitum.

\section{Preparation of crude khat extract}

Fresh khat twigs were purchased from a specific local farm in Maua, Meru County, Kenya on weekly basis and processed as follows: $60 \mathrm{~g}$ fresh khat twigs (leaves and shoots, peeled barks), were weighed and blended with 100 
$\mathrm{ml}$ of distilled water to give crude khat extract. The crude extract was then filtered using a sterile dish cloth. Five grams of glucose was then added to the filtrate and administered to the baboons.

\section{Experimental design}

Six $(n=6)$ adult olive baboons were mated with selected males during their normal cycling period. At 18 days postmating, the diagnosis of pregnancy was made with clinical criteria (amenorrhea with flat and red colored perineum) and ultrasound at day 18 to 24 . The pregnant baboons $(n=6)$ were randomly assigned into two groups; the treatment group $(n=3)$ were given crude khat extract at a dose of $5 \mathrm{~g} / \mathrm{kg}$ body weight per week for 8 weeks and the control group $(\mathrm{n}=3)$ were administered orally with $100 \mathrm{ml}$ of normal saline once a week by gavage method. The dosing was based on previously published information in humans and baboons (Al-Motarreb et al., 2002; Mwenda et al., 2006). All animals were sedated by intramuscular injection with $0.2 \mathrm{ml} / \mathrm{kg}$ body weight of Ketamix $(10 \%$ Ketamine $\mathrm{HCl}$ and $2 \%$ xylaxine). Administration of khat was started during the second trimester ( $2^{\text {nd }}$ month of pregnancy that is week 9 to week 16). Changes in animal physical health, body weight and blood pressure were monitored throughout the experimental period. Ten milliliters $(10 \mathrm{ml})$ of whole blood was collected weekly for the 8 weeks for separation of sera. On parturition, both the control and treatment groups were humanely sacrificed and both the liver and kidney were collected from the dams and the foetus for histopathological examinations.

\section{Weight, blood pressure and body temperature}

The animals were weighed, blood pressure and temperature monitored every time an animal was anesthetized to administer khat or saline. Weight was taken using a weighing scale and body temperature using a thermometer (rectal temperature). Blood pressure measurements were taken using an electronic a sphygmomanometer (VWR International, Leuven, Belgium). During blood pressure measurements, while a baboon was under anaesthesia, an inflatable cuff was placed smoothly around a shaved arm, at roughly the same vertical height as the heart while the baboon was lying in recumbence position and the arm supported horizontally. The cuff was then inflated until tight then slowly pressure in the cuff was released until stable readings were achieved and recorded as systolic and diastolic pressures.

\section{Liver and Kidney Function tests}

The effect of khat on liver and kidney functions were determined by assaying for various parameters. For liver function tests, the following parameters were assayed: liver enzymes (alanine aminotransferase (ALT), aspartate aminotransferase (AST), alkaline phosphate (ALP) and total and direct bilirubin. For kidney function test, the following parameters were assayed: creatinine, total protein, blood urea, Potassium and Sodium. All these parameters were assayed using human kits (Human Gesellschaft fur Biochemica und Diagnostica mbH, Germany) and protocols followed according to manufacturer's guidelines.

\section{Histopathological analyses}

The tissues (liver and kidney tissues) were collected from the dams and the foetuses, cut into cubes of $1 \mathrm{~mm}^{3}$ and preserved in formalin for histopathological analysis. The formalin preserved cubes were then embedded in paraffin and serially sectioned at $4 \mathrm{um}$. Ten sections were cut per cube, each section was put on a different slide and stained using hematoxylin and eosin ( $\mathrm{HE}$ ) then observed for histopathology under a microscope (Zeiss, Axiovert 10, model 1216-66-EL01-002, West Germany).

\section{Statistical analysis}

The levels of liver enzymes, bilirubin, creatinine, protein, urea and electrolytes were expressed as mean \pm standard error of mean (SEM). Student t-test was used to determine the effect of khat between the two groups. All tests were done using StatView software (version 5.0, SAS Institute Inc.). Differences with $p$ values $<0.05$ were considered significant at $95 \%$ confidence interval. 


\section{RESULTS}

\section{Weight, blood pressure and body temperature}

The results on effect of khat consumption on weight, blood pressure and body temperature changes are presented below (Table 1; Figure 1). The results indicated that khat induced a decrease in weight of the animals in the treatment group compared to those in the control group $(p<0.0001)$. the fetuses from the dams treated with khat had significantly low birth weight compared to fetuses $(p<0.02)$ from dams in the control group. There were no significant differences observed in body temperature changes in all groups throughout the experimental period. The treatment group had both the systolic and diastolic pressure slightly increased than the control group, however, the difference was not significant $(p>0.05$; Table 1$)$.

Table 1: Physiological effects of khat (Catha edulis) extract administration in Olive baboons during

\begin{tabular}{llll}
\multicolumn{3}{c}{ pregnancy } \\
\hline Parameter & Control & Treatment & p-value \\
\hline Diastolic pressure $(\mathrm{mm} \mathrm{Hg})$ & $35.33 \pm 2.433$ & $40.40 \pm 1.173$ & 0.109 \\
Systolic pressure $(\mathrm{mm} \mathrm{Hg})$ & $72.98 \pm 2.893$ & $78.00 \pm 2.664$ & 0.248 \\
Weight dams $(\mathrm{Kg})$ & $14.99 \pm 0.1342$ & $13.14 \pm 0.099$ & $0.0001^{*}$ \\
Weight Infants $(\mathrm{Kg})$ & $0.9 \pm 0.05$ & $0.60 \pm 0.05$ & $0.02^{*}$ \\
Temperature $\left({ }^{\circ} \mathrm{C}\right)$ & $36.52 \pm 0.1600$ & $36.56 \pm 0.0905$ & 0.7953 \\
\hline
\end{tabular}

${ }^{*}$ statistically significant difference

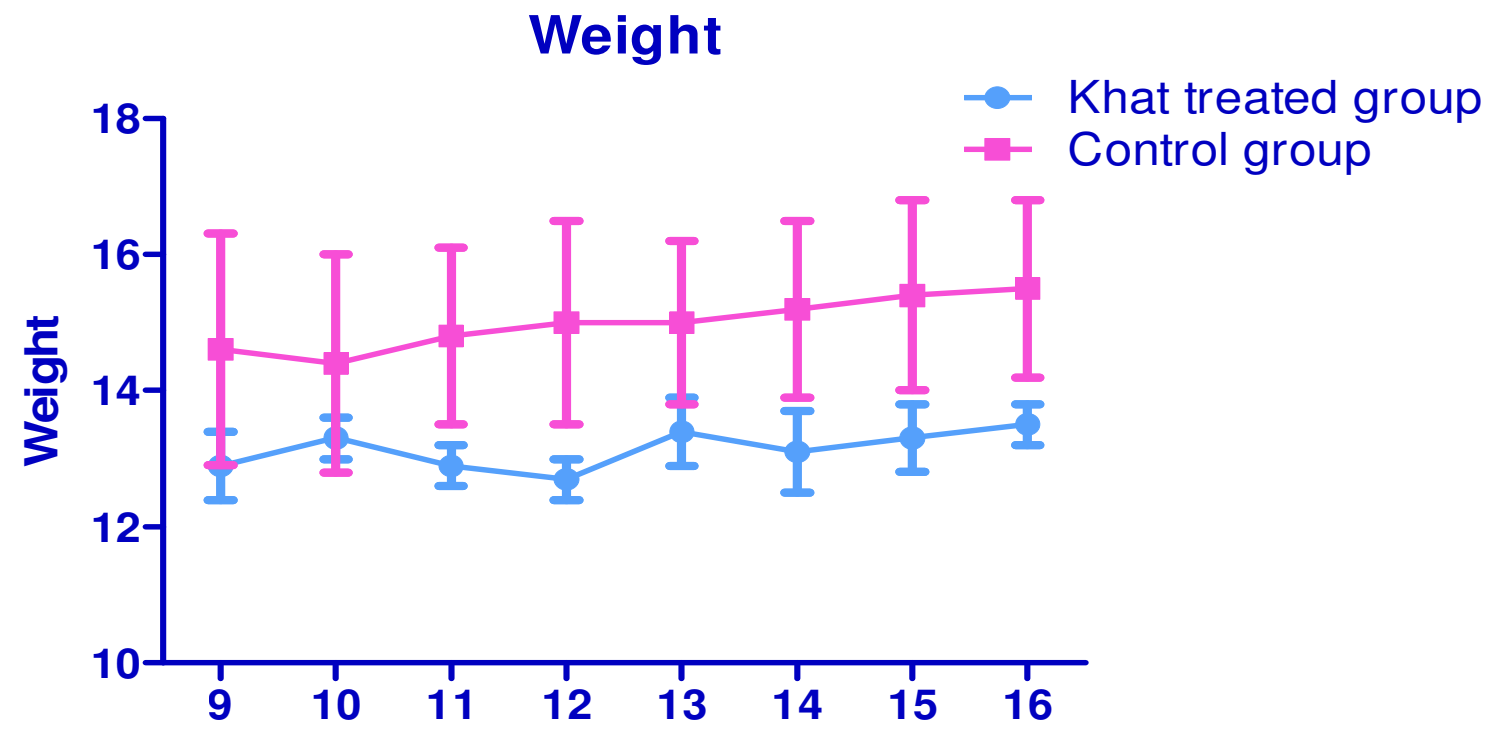

Time of pregnancy (weeks)

Figure 1: The weight of pregnant olive baboons given Khat and pregnant olive baboons on saline

\section{Liver and Kidney Function tests}

The liver and kidney function tests are shown in Table 2. An elevation in levels of ALP, AST and ALT of the treatment group as compared to the control were observed (Table 2). Total bilirubin and direct bilirubin did not show significant difference between the treatment and the control groups (Table 2). Albumin was significantly decreased in the treatment group with total protein showing no significance difference between the two groups ( $p>0.05$, Table 2). Creatinine and Urea were significantly increased in the treatment group while sodium compared was decreased in 
the treatment group compared to the control group (Table 2). There was no significant difference between the potassium levels of the treatment and the control group (Table 2).

Table 2: Effect of khat administration in olive baboons during the second trimester of pregnancy

\begin{tabular}{llll}
\hline Parameter & Control group $(\mathbf{n}=3)$ & Treatment group $(\mathbf{n}-3)$ & p- value \\
\hline Albumin $(\mathrm{gm} / \mathrm{dl})$ & $3.336 \pm 0.399$ & $2.065 \pm 0.083$ & $0.0075^{*}$ \\
Total protein $(\mathrm{gm} / \mathrm{dl})$ & $6.320 \pm 0.6064$ & $5.759 \pm 0.1606$ & 0.386 \\
Direct Bilirubin $(\mathrm{mmol} / \mathrm{l})$ & $0.3238 \pm 0.7331$ & $0.3175 \pm 0.074$ & 0.9532 \\
Total Bilirubin $(\mathrm{mmol} / \mathrm{l})$ & $0.7263 \pm 0.478$ & $0.7788 \pm 0.0586$ & 0.499 \\
ALP $(\mathrm{IU} / \mathrm{l})$ & $190.5 \pm 10.72$ & $936.3 \pm 95.01$ & $0.001^{*}$ \\
ALT $(\mathrm{IU} / \mathrm{l})$ & $22.94 \pm 0.8387$ & $26.75 \pm 0.8935$ & $0.0078^{*}$ \\
AST $(\mathrm{IU} / \mathrm{l})$ & $22.94 \pm 0.8387$ & $26.73 \pm 0.835$ & $0.0078^{*}$ \\
Creatinine $(\mu \mathrm{mol} / \mathrm{l})$ & $0.5625 \pm 0.0232$ & $0.8400 \pm 0.09$ & $0.0118^{*}$ \\
Urea $(\mu \mathrm{mol} / \mathrm{l})$ & $39.90 \pm 1.686$ & $49.10 \pm 3.403$ & $0.0294^{*}$ \\
Potassium $(\mathrm{mmol} / \mathrm{l})$ & $5.524 \pm 0.5019$ & $5.501 \pm 0.5019$ & 0.97 \\
Sodium $(\mathrm{mmol} / \mathrm{l})$ & $162.5 \pm 5.059$ & $81.53 \pm 3.899$ & $0.0001^{*}$ \\
\hline
\end{tabular}

${ }^{*}$ statistically significant difference

\section{Histopathological analyses}

Microscopic examination of liver tissues of controls group showed uniform hepatocytes, intact cytoplasm, prominent nuclei of cells and uncongested central vein (Figure 2A). In addition, no necrotic lesions or inflammatory signs were observed in these animals. In contrast, the liver tissue of the treatment group showed degenerative vacuolation and coagulative necrosis and degenerative changes in persisting parenchyma with congestion and hemorrhage. There were dilatation of sinusoids and mononuclear inflammatory infiltrates around the central vein and portal tracts including periportal fibrosis (Figure 2B, Figure 2C).

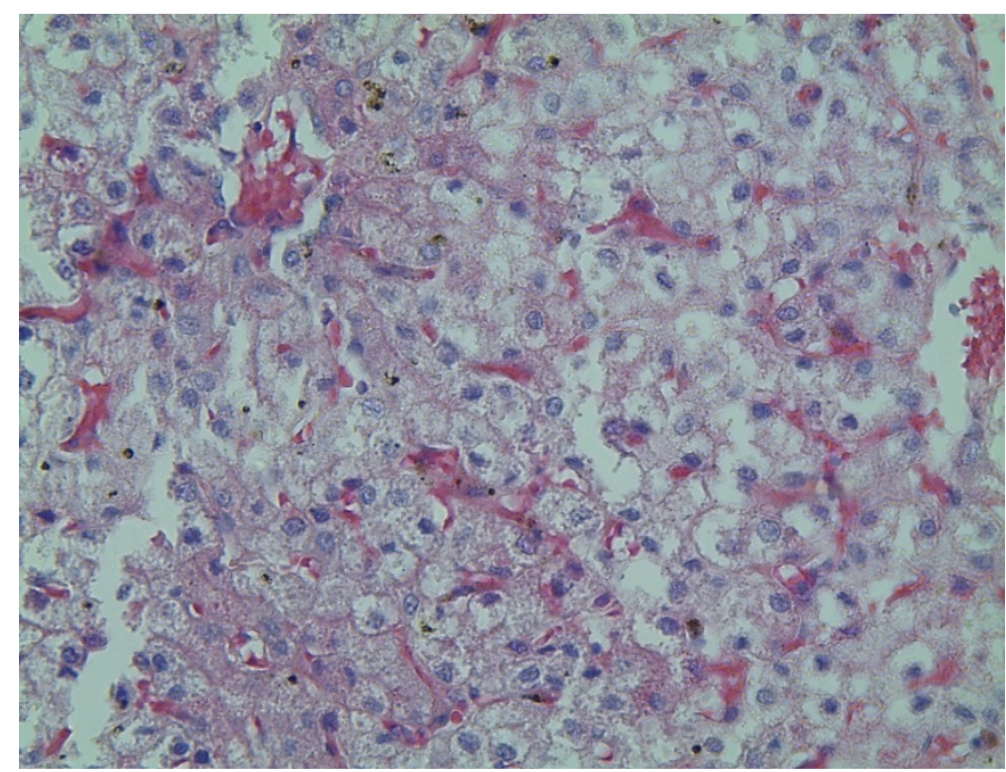

Figure 2A: A micrograph of hematoxylin and eosin stained liver section for control baboons showing normal liver morphology. (H \& E stain 20x) 


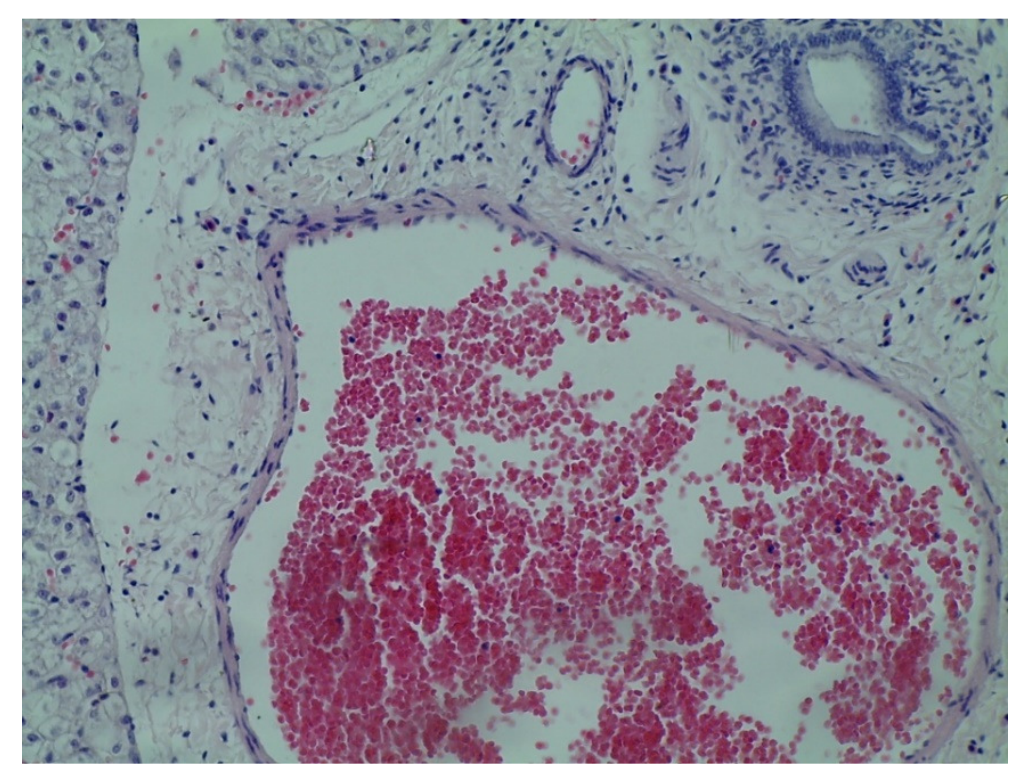

Figure 2B: A micrograph of hematoxylin and eosin stained liver section for khat treated baboons showing perivascular cuffing with periportal fibrosis. (H \& E stain 20x)

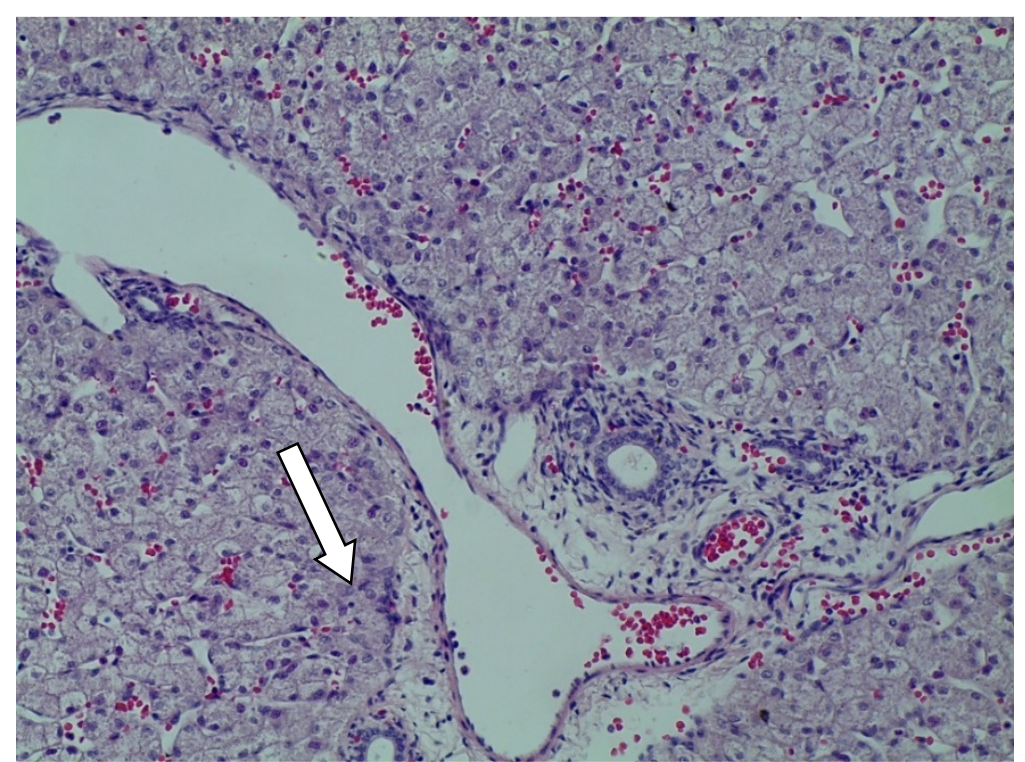

Figure 2C: A micrograph of hematoxylin and eosin stained liver section of infant from a khat treated baboons showing perivascular cuffing with periportal fibrosis. (H \& E stain 20x)

Microscopic examination of kidney tissue sections of control group demonstrated typical and normal histological features of tubules, glomerular capillaries and Bowman's capsule (Figure 3A). In contrast, kidney sections of treatment group showed histopathological changes. Such changes were characterized by atypical tubules, amorphous Malpighian corpuscles, and invasive infiltrative inflammatory cells. The glomerulus was degenerative and capillaries in Malpighian corpuscles were hypertrophied, some of them were destructed, and Bowman's capsules seemed dilated (Figure 3B, Figure 3C). 


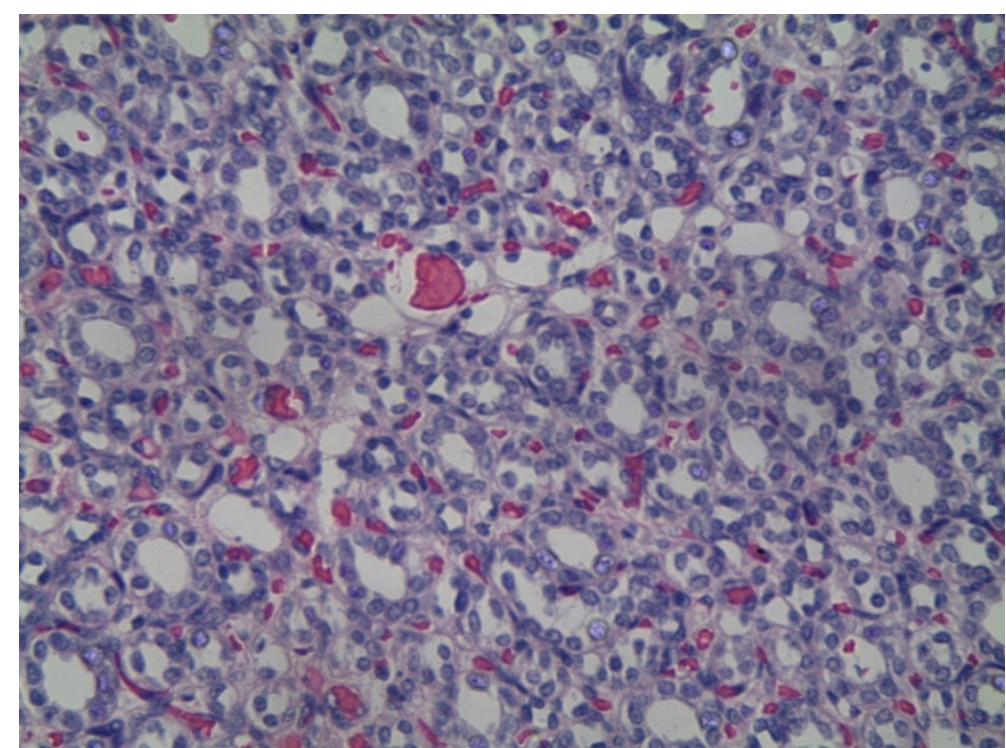

Figure 3A: A micrograph of hematoxylin and eosin stained kidney section for control baboons showing normal kidney morphology. (H \& E stain 20x)

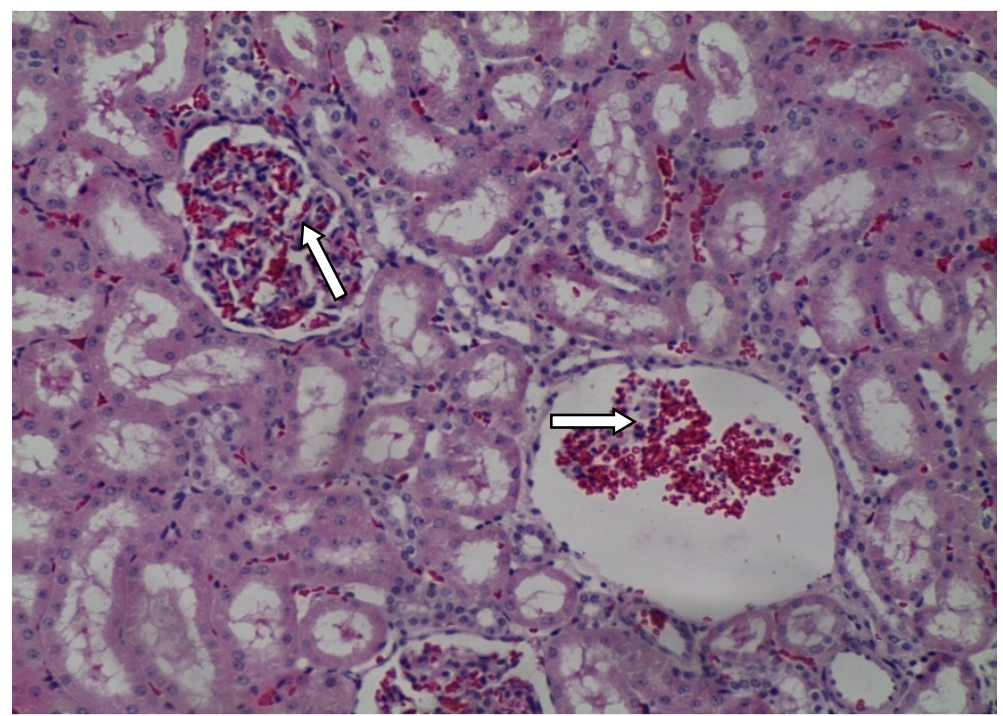

Figure 3B: A micrograph of hematoxylin and eosin stained kidney section for khat treated baboons showing degenerative glomerulus with red blood cell infiltration. (H \& E stain 20x) 


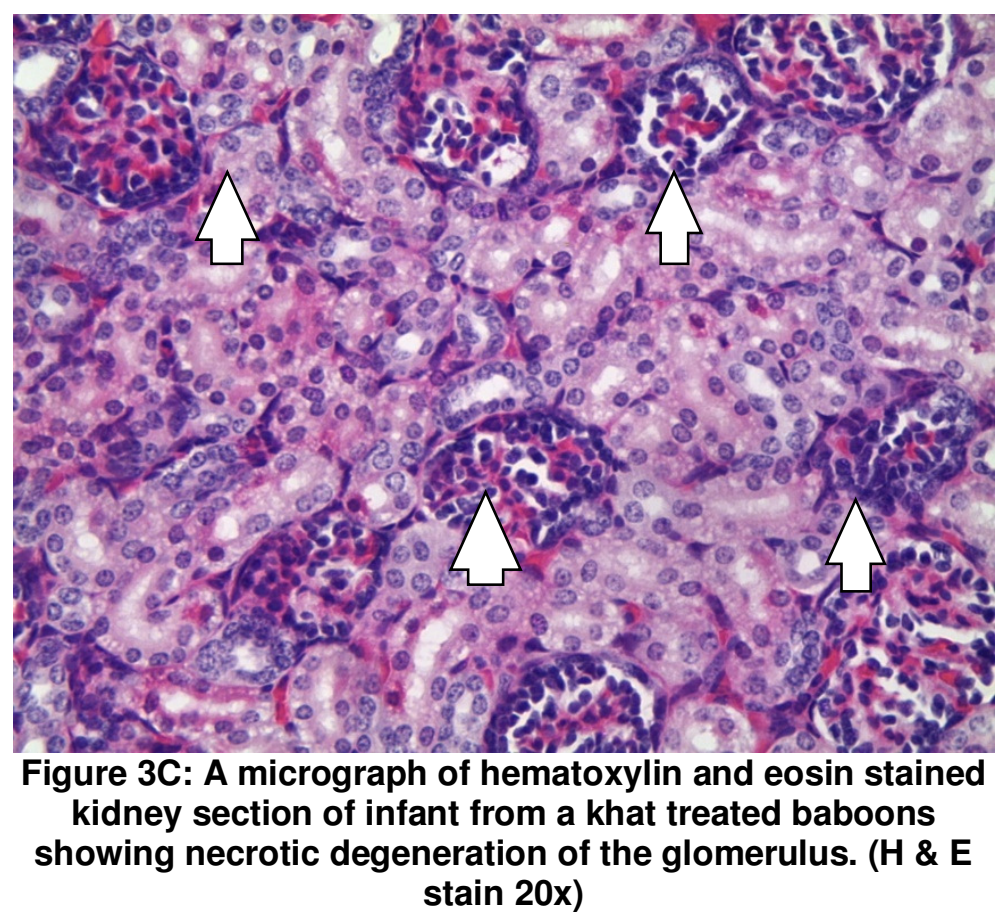

\section{DISCUSSION}

This study reports for the first time that consumption of khat during pregnancy alters liver and kidney functions and results in weight loss. As compared to the controls, the experimental animals had lower body weight. This finding was similar to previous studies in male baboons (Nyachieo et al., 2013) and other rodents (Shewamene and Engidawork, 2014; Dhaifalah and santavy, 2014). The reduced body weight could be due to reduced food absorption as documented elsewhere (Workineh et al., 2010).

Blood pressure and temperature showed similar results for control and experimental animals. Previously, blood pressure had been shown to increase in khat treated male baboons (Nyachieo et al., 2013). Similarly, the cathinone, found in khat has been shown to elevate diastolic blood pressure (Workineh et al., 2010).

and heart rate (Toennes et al., 2003). The difference between our study and previous studies could be due differences in dosage and frequency of administration. Our study used lower dose of $5 \mathrm{~g} / \mathrm{kg}$ body weight/week compared to the previous studies where $500 \mathrm{~g}$ per animal was used (Nyachieo et al., 2013).

An increase in the levels of alkaline phosphatase (ALP), aspartate aminotransferase (AST) and alanine aminotransferase (ALT) in pregnant olive baboons administered with khat. This suggests leakage of these enzymes into extracellular fluid as a result of toxic damage of liver tissue by the khat extract which may be compromising the membrane integrity of hepatocytes. Our finding is corroborated by a previous report in rodents (Alam et al., 2014). Tissue necrosis or membrane damage due to oxidative stress leading to increased levels of hepatic enzymes ALT, ALP and AST in the plasma (Al-Habori et al.,2002). This agrees with the histopathological examinations we obtained. In rats, similar findings have been shown while using hydroethanolic crude extract of khat shrubs (Al-Hashem et al., 2011) and crude extract of khat to rats (Al-Mehdar et al., 2012).

In this study, there was a significant decrease in serum albumin. The results agree with those reported earlier (Alam et al., 2014). Albumin is synthesized in the liver, and low serum albumin may be indicative of liver failure or diseases such as cirrhosis or chronic hepatitis. Hypoalbuminemia can also present as part of the nephrotic syndrome, in which protein is lost in the urine due to kidney damage. Moreover, low albumin levels can also be an indicator of chronic malnutrition or protein losing enteropathy (Al-Mehdar et al., 2012; Fahaid et al., 2011). Liver damage leading to decrease in albumin could be due to presence of some constituents of the Catha edulis that might have been converted to pro-oxidant metabolites decreasing the synthesis or activity of the antioxidant system in treatment group hence generation of free radicals by inhibiting synthesis of antioxidant enzymes, suggesting the liver damage observed (Fahaid et al., 2011).

Our study showed that there were similar levels of total bilirubin, direct bilirubin and total protein between the control and the treatment groups. This is in contrast with previous studies that have observed that oral administration of khat increases serum bilirubin (Fahaid et al., 2011) and decreased total protein (Al-Hashem et al., 2011). This difference could be due to the differences in the amount and duration of khat administration. 
Our study further established that khat has an effect on kidney function due to the presence of elevated levels of creatinine and blood urea nitrogen in the treatment group compared to controls. This can be attributed to impairment in tubular reabsorption, renal blood flow and glomerular filtration rate (Alam et al., 2014). Increase in serum urea, creatinine, and uric acid has been previously linked to kidney disease (Fahaid et al., 2011). There was significantly elevated levels of Sodium in the treatment group as compared to the controls but not in Potassium. The elevation of Sodium is an indicator of renal impairment as evidenced previously (Herny et al., 1998). This shows that khat may have chemical components that act directly or via mediation to induce over-hydration or induce secretion of vasopressin (Herny et al., 1998).

Pathological findings showed that indeed khat causes destruction of kidney structures characterized with infiltration of inflammatory cells, and degenerative glomerulus. The liver and kidney tissue pathologies observed in this study are consistent with those observed in rabbits (Islam et al., 1994; Al-Habori et al., 2002) However, the mechanism of khat toxicity in the liver and kidney is uncertain but generation of free radicals and oxidants can be implicated in inducing organotoxicites (Fahaid et al., 2011; Al-Zubairi et al., 2013).

\section{CONCLUSION}

The study has revealed that khat (Catha edulis) extract could have toxic effects on the biochemical components indicative of liver and kidney toxicity. However, the study findings were are not conclusive, therefore, further studies are indicated to establish the actual metabolisms and signalling pathways that are controlled by the chemical components present in khat.

\section{CONFLICT OF INTEREST}

The authors declares that they have no conflict of interest of in the publication of this paper.

\section{ACKNOWLEDGEMENTS}

We thank the National commission for Science Technology and Innovation (NACOSTI) of Kenya for their financial support of the project and Institute of Primate Research where the project was carried out.

\section{REFERENCES}

Ageely HM (2009). Prevalence of Khat chewing in college and secondary (high) school students of Jazan region, Saudi Arabia. Harm Reduct. J, 6(11):3.

Alam Shabbir M, Ahmad Ali Bin Jerah, Gowhar Nabi and Qayyum Husain (2014). Effect of khat (catha edulis) consumption on the functions of liver, kidney and lipid profile in male population of Jazan Region of Kingdom of Saudi Arabia. IJANS, 3(2):9-14.

Al-Habori M, Al-Aghbari A, Al-Mamary M, Baker M (2002): Toxicological evaluation of Catha edulis leaves: a long term feeding. J Ethnopharmacol., 83: 209-217 experiment in animals. .

Al-Hashem FH, Bin-Jaliah I, Dallak MA, Nwoye LO, Al-Khateeb M (2011). Khat (Catha edulis) Extract Increases Oxidative Stress Parameters and Impairs Renal and Hepatic Functions in Rats. Bahrain Medical Bulletin, 33(1):1-9.

Al-Mamary M, Al-Habori M, Al-Aghbari AM, Baker MM (2002). Investigation into the toxicological effects of Catha edulis leaves: a short term study in animals. Phytother. Res, 16:127-132.

Al-Mehdar A, El-Denshary E, Abdel-Wahha M (2012). Alpha Lipoic Acid and Alpha-Tocopherol Counteract the Oxidative Stress and Liver Damage in Rats Sub-Chronically Treated with Khat (Catha edulis) Extract. Global J. of Pharmacol. 6(2): 94-105.

Al-Motarreb A., Baker K. and Broadley KJ. (2002): Khat: pharmacological and medical aspects and its social use in Yemen. Phytother. Res, 16: 403-413.

Al-Zubairi A., Al-Habori M. and Al-Geiry A (2013). Effect of Catha Edulis (khat) Chewing on Plasma Lipid Peroxidation. J Ethnopharmacol., 87(1): 3-9.

D'Hooghe TM, Kyama CM, Chai D, Fassbender A, Vodolazkaia A, Bokor A, Mwenda JM (2009). Nonhuman primate models for translational research in endometriosis. J. Hum. Reprod. Sci. 16(2): 152-161. 
Dhaifalah I, Santavy J (2004). Khat habit and its health effect. A natural amphetamine. Biomedical Papers of the Medical Faculty of University of Palacky Olomouc Czech Republic , 148(1):11-15.

Fahaid H, Al-Hashem, Ismaeel Bin-Jaliah, Mohammad A, Dallak, Luke O Nwoye, Mahmoud Al-Khateeb, Hussein F Sakr, Refaat A Eid, Khalid S Al-Gelban, Hasan S Al-Amri, Mohamed A Adly (2011). Khat (Catha edulis) Extract Increases Oxidative Stress Parameters and Impairs Renal and Hepatic Functions in Rats. Bahrain Medical Bulletin., 33:1-9.

Herny JA, Fallon JK, Kicman AT, Hutt AJ, Cowan DA, Forsling M (1998). Low-dose MDMA ("ecstacy") induces vasopressin secretion. Lancet, 351(9118):1784.

Islam MW, al-Shabanah OA, al-Harbi MM and al-Gharably NM (1994): Evaluation of teratogenic potential of khat (Catha edulis Forsk.) in rats. Drug Chem. Toxicol. 17(1): 51-68.

Kassim S, Croucher, R (2009). Factors associated with dental and medical care attendance in UK resident YEMENI Khat chewers; a cross sectional study. BMC Public Health, 12: 486.

Kilkenny C, Browne WJ, Cuthill IC, Emerson M, Altman DG (2013). Improving bioscience research reporting: The arrive guidelines for reporting animal research. Animals, 4:35-44.

Mwenda JM., Owuor RA., Kyama CM., Wango EO., M'Arimi M. and Langat DK. (2006): Khat (Catha edulis) upregulates testosterone and decreases prolactin and cortisol levels in the baboon. $J$ Ethnopharmacol., 103:37984.

Nencini P, Ahmed AM (1989). Khat consumption: a pharmacological review. Drug Alcohol Depend. 23(1):19.

Nyachieo A, Chai DC, Deprest J, Mwenda JM, D'Hooghe TM (2007). The baboon as a research model for the study of endometrial biology, uterine receptivity and embryo implantation. Gynecol Obstet Invest. 64: 149-155.

Nyachieo A, Kiraithe MM, Spiessens C, Chai DC, Kiulia NM, D'Hooghe TM, Mwenda JM (2013). Short-Term Effects of High-Dose Khat on Sperm Parameters and Reproductive Hormonal Levels in Olive Baboons (Papio anubis). Gynecol Obstet Invest. 75: 109-114.

Pennings EJM, Opperhuizen A, van Amsterdam JGC (2008). Risk assessment of khat use in the Netherlands: A review based on adverse health effects, prevalence, criminal involvement and public order. Regul. Toxicol. Pharm, 52:199-207.

Shewamene Z, Engidawork E (2014). Subacute administration of crude khat (Catha edulis F.) extract induces mild to moderate nephrotoxicities in rats. BMC Complement Altern Med. 14:66.

Stevens VC (1997). Some reproductive studies in the baboon. Hum Reprod Update, , 3: 533-40.

Toennes SW, Harder S, Schramm M, Niess C, Kauert GF (2003). Pharmacokinetics of cathinone, cathine and norephedrine after the chewing of khat leaves. Br. J. Clin. Pharmacol, 56(1): 125-30.

Workineh Getahun, Teferi Gedif, FikruTesfaye (2010). Regular Khat (Catha edulis) chewing is associated with elevated diastolic blood pressure among adults in Butajira, Ethiopia: A comparative study. BMC Public Health, 10: 390 .

Cite this Article: Muema E, Kinyanjui P, Mbaria J, Nguta J, Chepkwony S, Kamau J, Onkoba N and Nyachieo A (2016). Toxicity and Safety of Khat (Catha edulis) Consumption during Pregnancy using Olive Baboons (Papio anubis) as Experimental Models: A Prospective Randomised Study. Greener Journal of Epidemiology and Public Health, 4(3): 061-070, http://doi.org/10.15580/GJEPH.2016.3.102116188 